\title{
Martin Bülow: response
}

\section{Douglas M. Ruthven ${ }^{1} \cdot$ Jörg Kärger ${ }^{2} \cdot$ Stefano Brandani $^{3} \cdot$ Enzo Mangano $^{3}$}

Accepted: 16 February 2021 / Published online: 5 March 2021

(c) The Author(s), under exclusive licence to Springer Science+Business Media, LLC part of Springer Nature 2021

Our paper (Sorption Kinetics: Measurement of Surface Resistance) was not intended as a general review of sorption rate measurements but rather as a commentary focused specifically on the problem of distinguishing experimentally between surface resistance control and internal diffusion control and the quantitative measurement of both these resistances. We did not address in any detail the physical origin of surface resistance or other general aspects of sorption kinetics. With respect to the volumetric/piezometric method, which has been widely used by many authors, we pointed out the value of the reduced pressure vs time plot for discrimination between the two mechanisms but, to avoid a lengthy digression, we did not discuss in any detail either the experimental technique or the various approaches that have been developed for analysis of the experimental data.
The extensive bibliography provided by Martin Bülow will serve as a useful source of data for any readers who wish to explore these topics in greater detail, but these should be read in conjunction with the careful analysis of the importance of the flow through the valve, particularly for fast diffusion systems such as Benzene in $\mathrm{NaX}$ [1].

\section{Reference}

1. Brandani, S.: Analysis of the piezometric method for the study of diffusion in microporous solids: isothermal case. Adsorption 4, 17-24 (1998)

Publisher's Note Springer Nature remains neutral with regard to jurisdictional claims in published maps and institutional affiliations.

This reply refers to the comment available online at https://doi. org/10.1007/s10450-021-00309-9.

Douglas M. Ruthven

druthven@umche.maine.edu

1 Department of Chemical Engineering, University of Maine, Orono, ME 04469, USA

2 Faculty of Physics and Geosciences, University of Leipzig, 04103 Leipzig, Germany

3 School of Engineering, University of Edinburgh, Edinburgh EH9 3JL, UK 